\title{
RESSONÂNCIAS NO PROCESSO DE DEMOLIÇÃO DO PALÁCIO MONROE
}

Daniel Levy de Alvarenga ${ }^{80}$

Artigo recebido em: 28/05/2018

Artigo aceito em: 29/06/2018

\section{RESUMO:}

Todo patrimônio material possui uma dimensão imaterial que é o reflexo da atribuição de valor que as pessoas conferem a um determinado bem cultural. Assim, a noção de patrimônio permite tanto uma abordagem material quanto imaterial, reunindo em si estas duas dimensões. Este aspecto da subjetividade ou da imaterialidade do patrimônio se relaciona, de certa forma, com a questão da ressonância, ou seja, com o grau de reconhecimento de um determinado patrimônio cultural junto aos diversos setores da população. O Palácio Monroe, prédio público de estilo arquitetônico eclético situado no Rio de Janeiro e que abrigou a Câmara dos Deputados por 8 anos e o Senado Federal por 35 anos, foi demolido em 1976 durante o regime autoritário brasileiro. Neste artigo apresentaremos como foi realizada a sua demolição e qual foi a sua ressonância perante a população da cidade.

PALAVRAS-CHAVE:

Patrimônio Cultural; Palácio Monroe; Demolição; Ressonância.

\section{ABSTRACT:}

Every material heritage has an intangible dimension that is the reflection of the attribution of value that people confer to a cultural good. The notion of heritage allows both a material and immaterial approach, bringing together these two dimensions. This aspect of the subjectivity or the immateriality of the heritage is related to the resonance, to the degree of recognition of a certain cultural heritage along the sectors of the population. The Monroe Palace, a public building of eclectic architectural style located in Rio de Janeiro, which housed the Chamber of Deputies for 8 years and the Federal Senate for 35 years, was demolished in 1976 during the Brazilian authoritarian regime. In this article we will expose how the demolition was carried out and how was its resonance with the population of the city.

\section{KEYWORDS:}

Cultural Heritage; Monroe Palace; Resonance.

$$
* * *
$$

\section{INTRODUÇÃO}

\footnotetext{
${ }^{80}$ Doutorando em Ciências Jurídicas Políticas pela Universidade Autônoma de Lisboa (UAL). Mestre em História pela Universidade Federal do Estado do Rio de Janeiro (UNIRIO). Graduado em Direito e em História pela Pontifícia Universidade Católica do Rio de Janeiro (PUC-Rio). Integrante do Grupo de Estudos e Trabalhos sobre Políticas de Preservação do Patrimônio Cultural (UNIRIO). Currículo Lattes: http://lattes.cnpq.br/0363422757103951.
} 


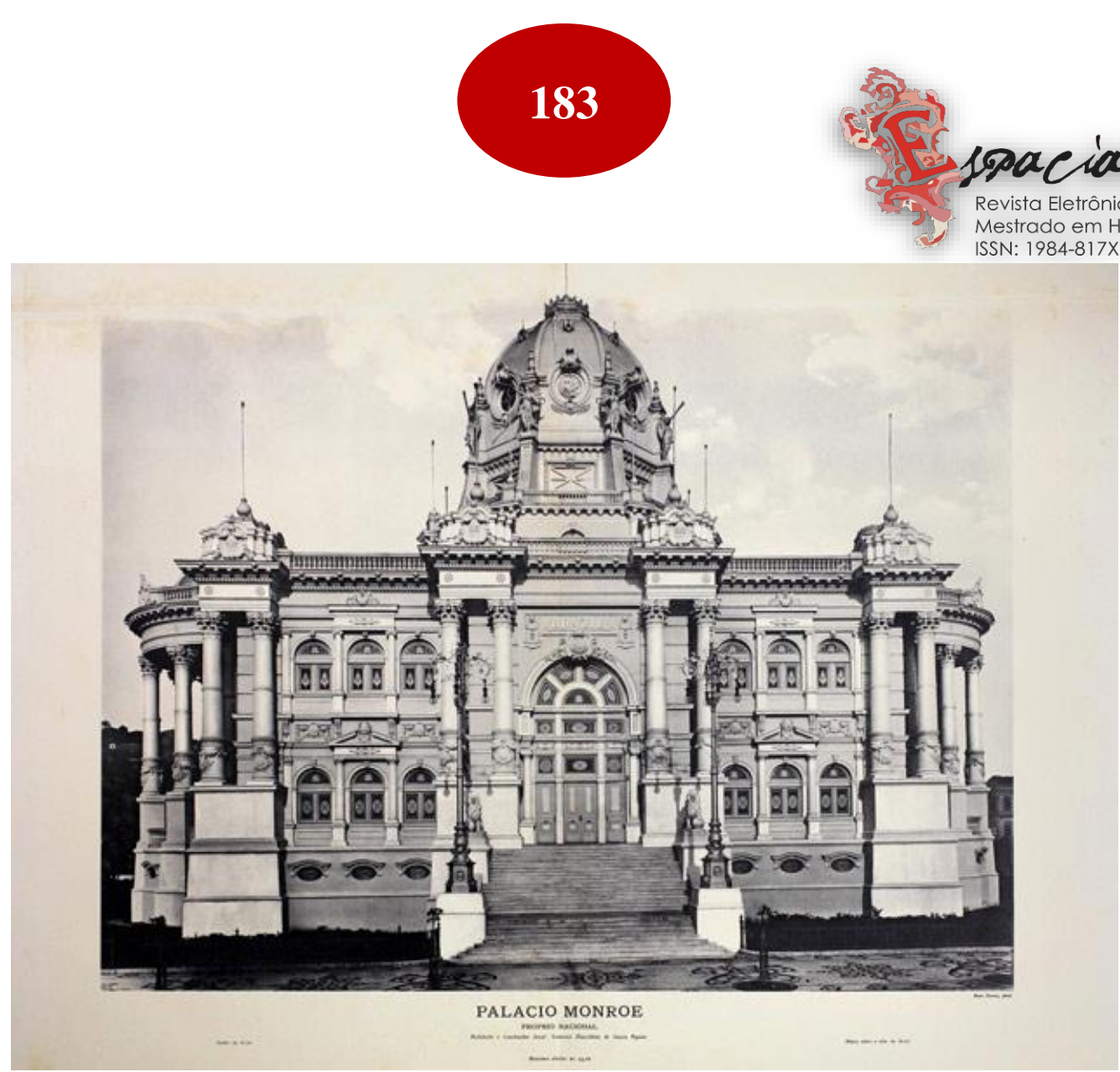

Figura 1- Palácio Monroe (Marc Ferrez)

Se considerarmos o fenômeno da nação como sendo algo característico da modernidade surgido no final do século XVIII e início do século XIX, o nacionalismo brasileiro, como afirma Benetict Anderson (2008, p. 21), se desenvolveu tardiamente e de maneira idiossincrática. Enquanto nossos vizinhos na América do Sul aderiram aos ideais iluministas para romper com seu passado colonialista e se alinhar à moderna ideia de nação através da fundação de Estados nacionais republicanos, no Brasil foi estabelecida uma monarquia constitucionalista e escravista, com poucas rupturas com a forma de dominação praticada pela antiga metrópole.

A "comunidade imaginada" brasileira foi construída de maneira lenta e gradual durante o todo século XIX e início do século XX, sempre mediada pelas elites. Tomando como base alguns dos elementos constitutivos da nação e da consciência nacional propostos por Benetict Anderson, perceberemos que a imprensa brasileira teve nascimento e desenvolvimento tardios e que o primeiro censo nacional somente foi realizado em 1872. Além disso, o Brasil somente aboliu formalmente a escravidão em 1888 e a adesão ao modelo republicano ocorreu no apagar das luzes do século XIX. Como afirma István Jancsó (2003, p. 15) "hoje é assente que a formação do Estado nacional brasileiro resultou de um processo de grande complexidade, ao qual é equivocado reduzir à ruptura, em 1822, 
do pacto que integrava as partes da América no império português".

Nesta complexidade que foi o processo de formação da nação e do estado no Brasil, a ideia de cidade capital ganhou importância, pois deveria servir de modelo para o país, além de fortalecer a construção da imagem de uma nação pronta para ingressar, mesmo que tardiamente, no cenário civilizatório ocidental. Desta forma, a nova função da cidade capital do Rio de Janeiro justificou uma série de intervenções públicas ocorridas no final do século XIX e início do século XX com o objetivo de normatizar, regrar e disciplinar o espaço para que este representasse os novos ideais almejados. Assim, o Rio de Janeiro passou a ter grande relevância no quadro urbanístico brasileiro, pois representava um símbolo da nação, uma cidade-síntese de um país imaginado. O Rio foi o espaço onde o Estado nacional se firmou simbolicamente como centro do poder institucional e como representação da própria nacionalidade que se queria fundar. Mas esta cidade-símbolo, que abrigou a capital da República e antes a capital do Império, foi também o lugar que sofreu as interferências urbanas mais profundas por parte do poder público.

A reforma realizada por Pereira Passos no início do século XX, cuja obra principal foi a abertura da Avenida Central, possibilitou a efetiva introdução do estilo arquitetônico eclético no Brasil. Quase todas a edificações da Avenida foram escolhidas através de um concurso de fachadas, procedimento pouco conhecido no meio técnico brasileiro, e que "tinha como finalidade manter uma uniformidade de pensamento e forma, resultando num dos conjuntos mais expressivos da arquitetura da Primeira República" (ATIQUE, 2011, p.1). O final da Avenida foi o lugar escolhido por Pereira Passos para a construção do Teatro Municipal, localização já consagrada na tradição artística da cidade pela presença do Teatro Lírico. A alocação desta instituição cultural neste espaço privilegiado, somando-se aos prédios públicos, também de estilo eclético, da Escola de Belas-Artes, da Biblioteca Nacional, da Câmara Municipal, do Supremo Tribunal Federal e do Palácio Monroe, então denominado de Pavilhão São Luiz, fez com que o local adquirisse uma forte significação política e cultural, caracterizando-se como o centro "civilizador" do Rio de Janeiro. A lógica que guiava toda essa transformação, e que não passava necessariamente pelos desejos dos habitantes da cidade, era a lógica da modernidade e da representação de uma nação que almejava ingressar no seleto grupo dos países civilizados. E o Palácio Monroe foi um símbolo desta aspiração. 


\section{5}

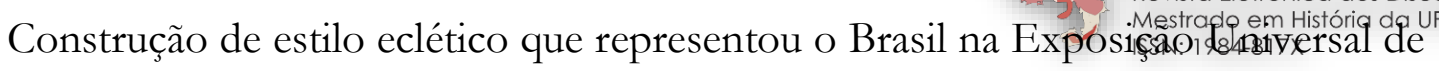
Saint Louis, nos EUA, em 1904, o Palácio Monroe (então denominado de Pavilhão São Luiz) foi realocado no Rio de Janeiro, na Avenida Central, atual Avenida Rio Branco, em 1906 (figura 1). O prédio, que teve sua arquitetura premiada nos EUA, sediou a III Conferência Pan-Americana, abrigou a Câmara dos Deputados por 8 anos e o Senado Federal por 35 anos. Após a transferência da capital para Brasília, uma representação do Senado, denominada de "Senadinho", continuou a ocupar o edifício público, juntamente com outros órgãos federais. O Monroe foi demolido em 1976, em pleno regime autoritário, após intensos debates acerca da preservação do conjunto arquitetônico remanescente da abertura da Avenida Central ocorrido no IPHAN - Instituto do Patrimônio Histórico e Artístico Nacional e que envolveu diversas entidades da sociedade civil como o Clube de Engenharia do Rio de Janeiro, o Instituto de Arquitetos do Brasil (IAB) e o Jóquei Clube Brasileiro.

Como uma última tentativa de salvar o prédio, em dezembro de 1975, 162 arquitetos e engenheiros expuseram seu inconformismo com relação à demolição do Palácio Monroe através de um Manifesto pela sua preservação. Além disso, diversas entidades públicas e privadas manifestaram o interesse em ocupar o prédio, considerando a falta de espaços para acomodar os órgãos federais presentes na antiga capital. Tudo isso de nada adiantou. Em resposta a um desses pedidos de ocupação, o então ministro chefe do gabinete presidencial, Golbery do Couto e Silva, esclareceu que cumpria-lhe obedecer "recomendações do Senhor Presidente da República no sentido da demolição do prédio e consequente transformação da área em logradouro público" (AGUIAR, 1976, p. 212).

Todo patrimônio material possui uma dimensão imaterial que é o reflexo da atribuição de valor que as pessoas conferem a um determinado bem cultural. Maria Cecília Londres Fonseca (2001, p. 112) ensina que "os bens culturais não valem por si mesmos, não têm um valor intrínseco. $\mathrm{O}$ valor lhes é sempre atribuído por sujeitos particulares e em função de determinados critérios e interesses historicamente condicionados". Assim, a noção de patrimônio permite tanto uma abordagem material quanto imaterial, reunindo em si estas duas dimensões.

Este aspecto da subjetividade ou da imaterialidade do patrimônio se relaciona, de 
certa forma, com a questão da ressonância, ou seja, com o grau de recónhlMestrado em História da u determinado patrimônio cultural junto aos diversos setores da população. Neste artigo exporemos como foi o processo de demolição do Palácio Monroe e qual era o grau de ressonância que este patrimônio possuía perante a população. Utilizamos como fonte para a composição do texto o livro de Louis de Souza Aguiar, filho do engenheiro e projetista do Palácio, publicado em 1976 imediatamente no pós-demolição: "Palácio Monroe: da Glória ao Opróbrio". O livro, de cunho investigativo e em tom de denúncia, coleta documentos, matérias jornalísticas e relaciona fatos que, segundo o autor, apontam para a negligência e o descaso das autoridades e para as pressões feitas por parte do setor privado, que acabaram resultando no apagamento acelerado do Palácio. Outra fonte utilizada foi o processo de tombamento $\mathrm{n}^{\circ}$ 860-T-72, disponibilizado na versão digital pelo Arquivo Central do IPHAN, Seção do Rio de Janeiro, que contém pareceres, laudos, cartas e ofícios relativos ao conjunto arquitetônico da Avenida Central, além de diversas notícias veiculadas pelos periódicos da cidade do Rio de Janeiro a respeito do Palácio Monroe na primeira metade da década de 1970.

\section{O PROCESSO DE DEMOLIÇÃO DO MONROE}

A palavra demolição possui um sentido eminentemente negativo associado a uma espécie de destruição violenta e arrasadora em contraposição com aquilo que é construtivo e edificante. Alberto Goyena (2015, p. 18) afirma que suas representações mais vulgares "revelam empenas mutiladas, fachadas arruinadas, coberturas estragadas, portarias desfeitas, lembranças pulverizadas - são imagens que frequentemente despertam, ilustram ou traduzem sentimentos nostálgicos de perda e morte". O mesmo autor, porém, ensina que a palavra nem sempre carregou esta conotação:

\footnotetext{
Demolitio é a tarefa de demover, de transladar, como se faz com um monumento que repousava sobre um pedestal. O verbo demoliri deriva de moliri, que significa construir, cuja raiz mole é "grande estrutura". Já seu prefixo de- conota "pôr abaixo", "pôr atrás", mas também "reverter". Neste último sentido, mais do que como uma destruição da arquitetura, a demolição se apresenta como uma construção em reverso - uma espécie de desarquitetura -, indicando também a possibilidade de pensá-la como um ato criativo de translado (GOYENA, 2015, p. 18).
}

Assim, a demolição, como palavra e categoria de pensamento, estimula a reflexão 


\section{7}

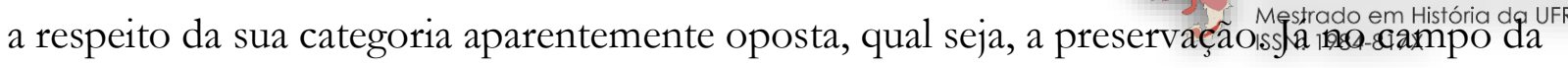
memória, a demolição é frequentemente relacionada ao perigo do esquecimento, ao risco de desaparecimento ou a possível perda de identidade e cultura. Apesar de concordamos com a proposta de Goyena (2010, p. 3) no sentido de pensar a demolição de modo menos acusatório, uma vez que as políticas patrimoniais devem "inevitavelmente realizar seleções, que as concepções de patrimônio e preservação apresentam profundas divergências segundo o contexto social e que a memória pressupõe não só a lembrança, mas também o esquecimento", no caso do Palácio Monroe a sua demolição teve um alto grau de violência, tanto material quanto simbólica.

Com a extinção da representação do Senado nas instalações do Palácio, o governo federal, através do então Serviço de Patrimônio da União (SPU), realizou no final do ano de 1975 uma concorrência pública para efetivar a demolição do Monroe. A ideia não era gastar dinheiro com a empreitada, pois o certame seria vencido pela empresa que oferecesse o maior preço para arrematar o Palácio e, posteriormente, se remunerar com a venda do material uma vez que diversos componentes do edifício possuíam relevante valor monetário como, por exemplo, a grande abóbada central, os lambris e portas em madeira de lei, as peças e esculturas entalhadas, os lustres em metal, cristal e opalina, a escadaria de mármore, vitrais diversos e toda estrutura de ferro que possibilitou a remoção do então Pavilhão São Luiz dos EUA para o Brasil, em 1904. O Monroe foi demolido entre janeiro e agosto de 1976 pela firma demolidora especializada chamada Aghil Comércio de Ferro Ltda. que arrematou a demolição do Palácio por Cr\$191.000,00, com direito à venda de todos os materiais, mobiliário e peças que, segundo estimativas do Jornal Diário de Notícias, valeriam Cr\$ 9.000.000,00 (DIÁRIO DE NOTÍCIAS, 11 jan. 1976, p.10).

Antes de colocar o prédio abaixo a empresa teve que realizar um minucioso processo de retirada das partes internas que chegou a ser considerado por seus funcionários como um "verdadeiro artesanato", pois na construção do prédio teria sido "utilizada a mesma técnica de estuque dos Arcos da Lapa e por esse motivo a desmontagem é quase toda feita à mão" (JORNAL DO BRASIL, 11 jan. 1976, p. 22). Além disso, se descobriu que as paredes do Monroe não eram comuns, pareciam de gesso, mas na verdade eram de um material bastante resistente à base de massa cozida com óleo de baleia, armado sobre telas de arame. Algumas destas paredes eram muito espessas. Os 30 operários contratados pela empresa nesta fase inicial e que trabalhavam sem quaisquer condições de segurança, 


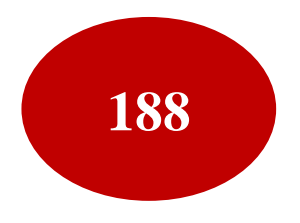

praticamente não utilizaram britadeiras, somente marretas e picaretas. Som Mestrado em Histórićda U U U das estruturas metálicas do edifício desaconselharem qualquer tipo de implosão (figuras 2 e 3).

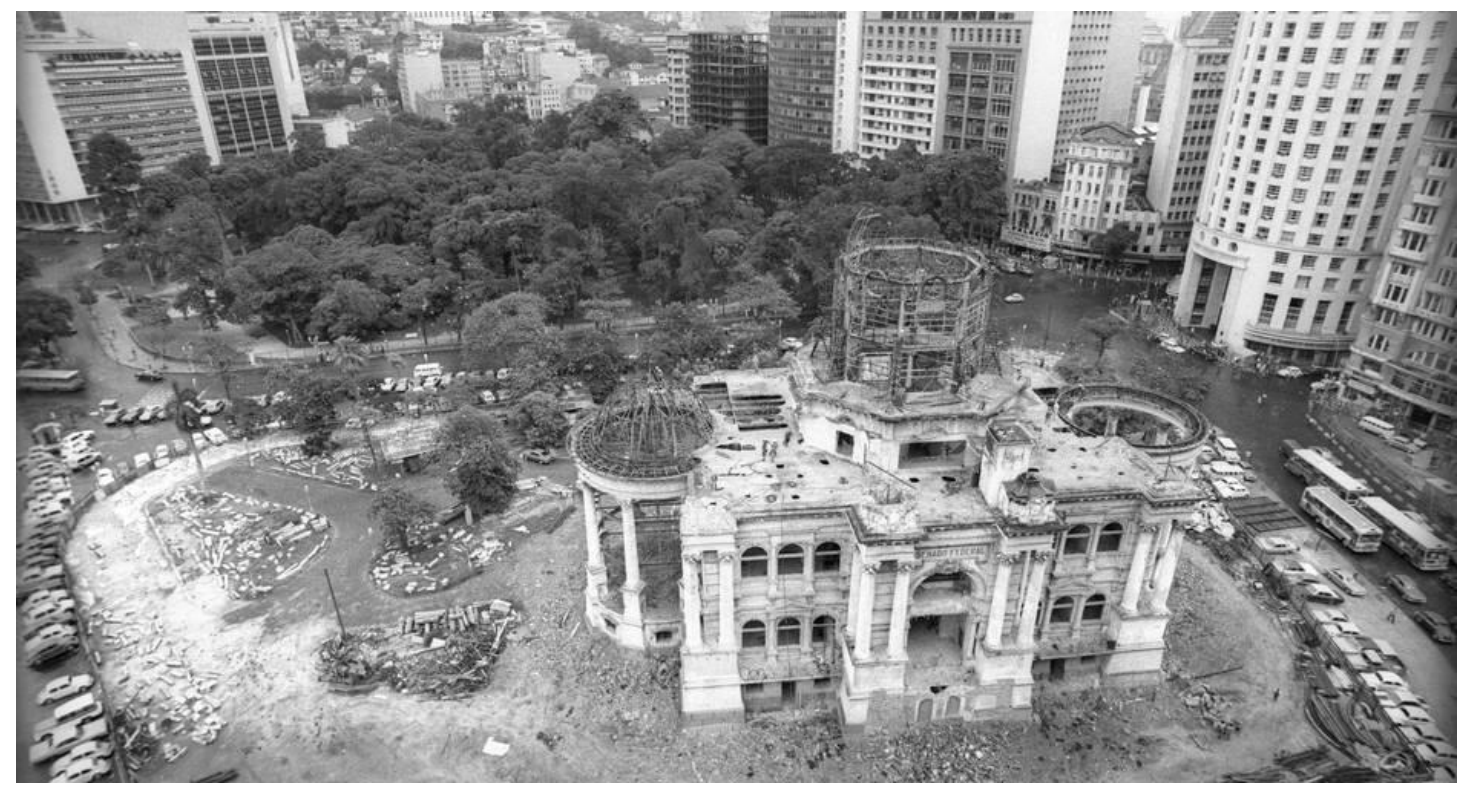

Fig. 2: início da demolição (Alcyr Cavalcanti/Acervo O Globo)

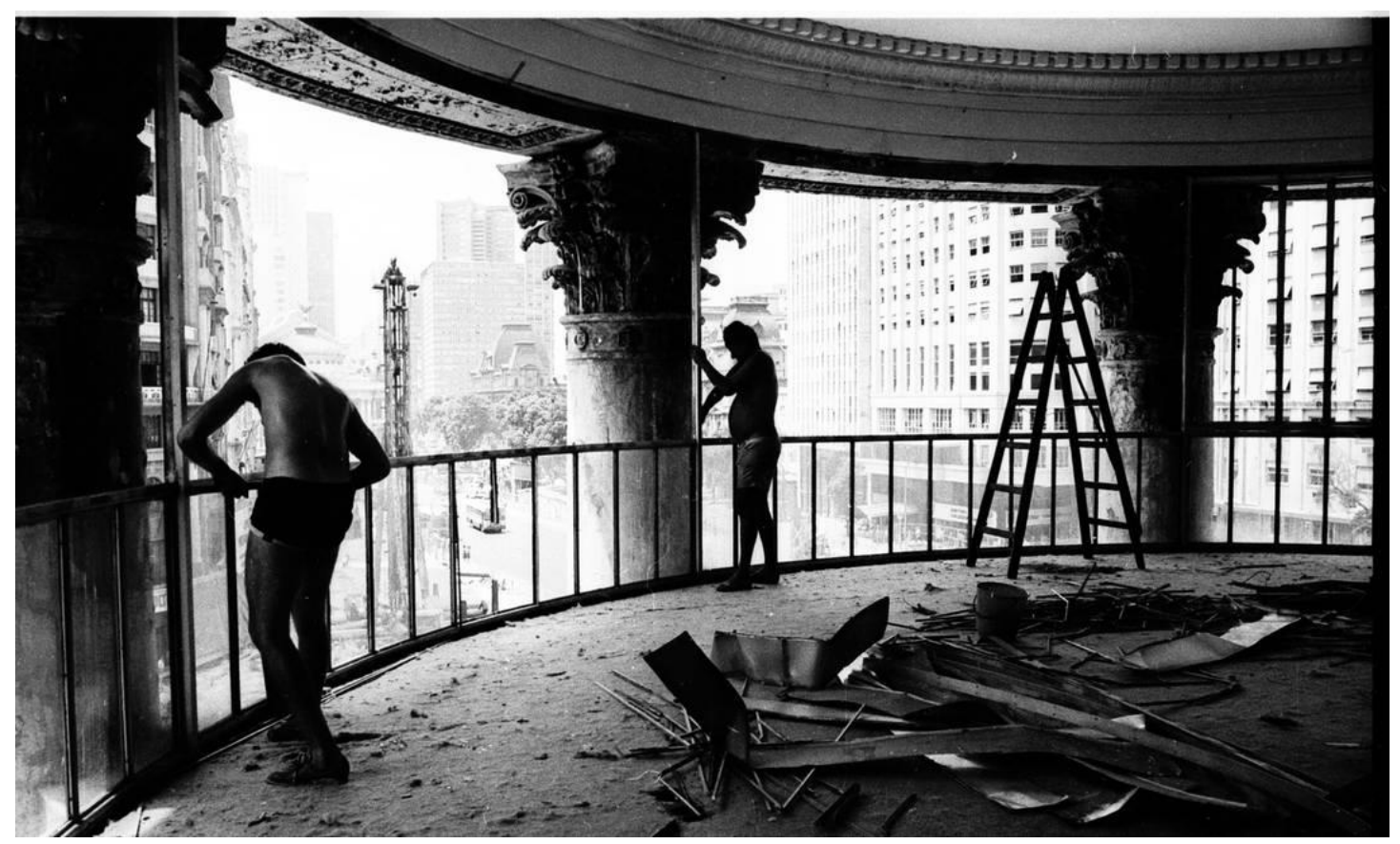

Fig. 3: "trabalho artesanal" de desmonte (José Vidal/Acervo O Globo)

Os vitrais do plenário do Senado de autoria do pintor Henrique Campos Cavaleiro, trabalhados a fogo em vidro belga e opalina, foram desmontados por uma empresa 


\section{9}

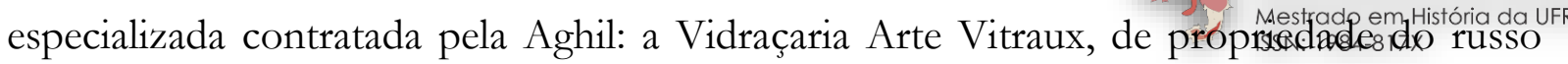
Jonas Slichticas, que durante muitos anos trabalhou com o Henrique Campos Cavaleiro. Antes mesmo de iniciada a retirada já tinham sido realizadas duas propostas de particulares interessados em adquirir o vitral principal, avaliado em $\mathrm{Cr} \$ 120.000,00$. Este valor era quase o preço total pelo qual a Aghil tinha arrematado o Palácio. Os 16 vitrais internos estimados em Cr\$ 6.000,00 por unidade - e um vitral lateral de 15 metros quadrados, o único existente no Brasil em homenagem à Proclamação da República (figura 4), foram avaliados em Cr\$50.000,00 (O GLOBO, 20 jan. 1976, p. 15) e depois por Cr\$120.000,00 (O GLOBO, 12 fev. 1976, p. 11).

Os filhos do pintor Henrique Cavaleiro também estavam interessados em comprar os vitrais para preservar o acervo de "singular valor artístico" deixado pelo pai, pois eram as únicas peças no gênero em toda a obra do artista. O russo Jonas Slichticas, dono da Vidraçaria Arte Vitraux, e o xilogravador e crítico de arte Quirino Campofiorito apelaram em reportagem veiculada no $O$ Globo para que o Governo comprasse de volta todas as peças que, segundo Campofiorito, "deveriam estar no Museu Nacional de Belas-Artes” (O GLOBO, 20 jan. 1976, p. 15). Sabe-se que pelo menos um dos vitrais do plenário foi comprado por um restaurante da Barra da Tijuca e outros por um grupo de arquitetos paulistas.

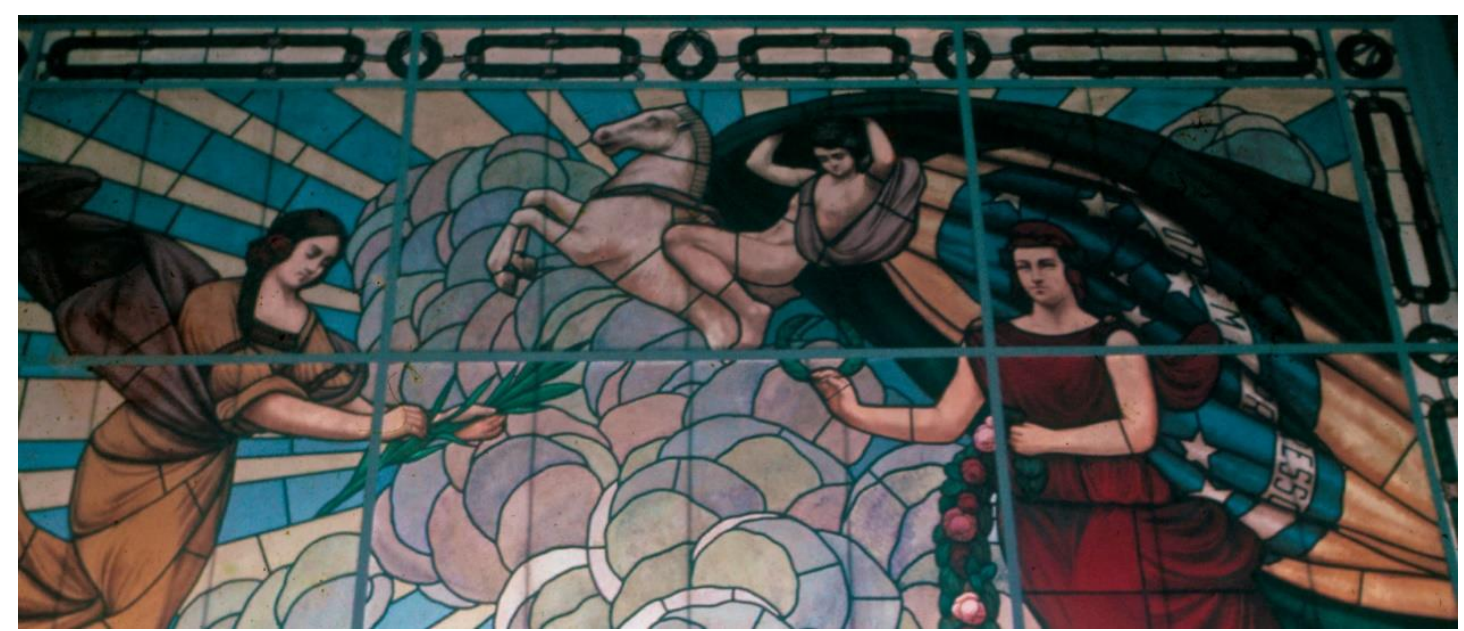

Fig. 4: vitral em homenagem à República (Acervo Olinio Coelho)

Outras obras de arte e o mobiliário interno também foram removidos e vendidos, além dos pisos, aramados, elevadores, portas e gradis. Os seis primeiros anjos de bronze retirados da cúpula, medindo três metros de altura e pesando 150 quilos cada, foram 


\section{0}

comprados rapidamente por Cr\$10.000,00, a unidade (O GLOBO, 12 Mestrad:

Cerca de 2 mil metros quadrados de assoalho foram ensacados e vendidos a um grupo de japoneses, "atraídos pelos tacos de peroba do campo formando desenhos graciosos" (JORNAL DO BRASIL, 11 jan. 1976, p. 22). Uma escadaria de ferro, em caracol, foi vendida a granel para particulares interessados em decorar suas casas, à base de Cr\$ $5.000,00$ o metro.

A retirada dos leões esculpidos em massa carrara foi um trabalho delicado que demorou alguns dias. Das quatro esculturas dos leões, inicialmente duas foram vendidas a Luís Carlos de Adriano Franco, um fazendeiro de Uberaba, Minas Gerais. O fazendeiro adquiriu os leões por Cr\$20.000,00 para satisfazer a vontade de sua mãe "Dona Olésia", pois o leão era o símbolo que o seu marido tinha escolhido para a próspera fazenda de gado chamada São Geraldo: "é uma espécie de homenagem póstuma de mamãe e de toda a família. As peças serão colocadas no pórtico de nossa fazenda-sede, em Uberaba”, disse Luis Carlos a reportagem do O Globo (O GLOBO, 8 jan. 1976, p. 10). Além dos leões, o fazendeiro comprou por Cr\$20.000,00 o portão de ferro que decorava a entrada principal do Palácio e uma estátua de anjo. Acabou ganhando de "presente" do Sr. Antônio Gonçalves da Silva, funcionário encarregado da demolição, a mureta que decorava o último andar do prédio. Como tinha sido a primeira vez que o empresário rural tinha comprado alguma escultura na sua vida, pretendia promover uma grande festa quando chegasse na fazenda São Geraldo. Segundo Alberto Goyena os objetos, partes ou entulhos retirados de uma demolição podem ser revalorizados como matéria-prima, coleções, monumentos ou patrimônios em outros ambientes:

Se a ideia de permanência na arquitetura é uma ficção, também o é a da tábula rasa, pois, decerto, a matéria demolida e fragmentada não desaparece do tecido urbano, mas segue um percurso criativo e dinâmico capaz de mostrar o quanto é sólido o postulado segundo o qual a consciência do desaparecimento arquitetônico desperta também o interesse patrimonial (GOYENA, 2015, p. 83).

O destino dos leões do Monroe é um bom exemplo deste "percurso criativo" sugerido por Goyena. As outras duas esculturas dos leões tinham sido compradas por um outro fazendeiro e transportadas para o município de Teresópolis, no estado do Rio de Janeiro. Algum tempo depois, o fazendeiro de Uberaba que havia comprado dois leões também adquiriu os outros dois leões que estavam em Teresópolis e os levou para um sítio de sua propriedade na Avenida Brasil, na cidade do Rio de Janeiro. Sergio Fridman (2011, 


\section{1}

p. 62) relata que anos mais tarde, em 1983, foi intenção de Luís Carlos Fiestrado em História da UFRN

leões num empreendimento hoteleiro que seria construído no bairro da Urca, no local onde funcionou a TV Tupi. O projeto era demolir o prédio para construir um hotel pertencente a rede internacional Holiday Inn, com 10 andares e 280 apartamentos, e acabou não se concretizando. Luís Carlos, dono dos quatro leões, resolveu vender dois deles para um cidadão de Ibiúna, no estado de São Paulo, chamado Sr. Salustiano. Finalmente, estes dois leões foram adquiridos pelo Instituto Ricardo Brennand, com sede em Recife, Pernambuco, onde atualmente se encontram (figuras 5, 6, 7 e 8).

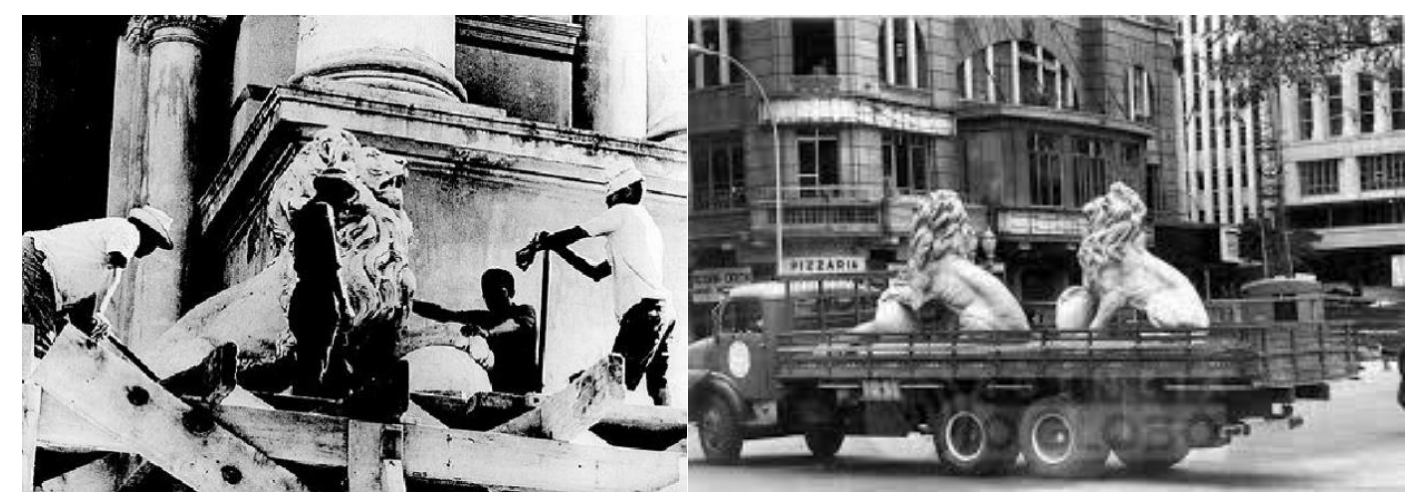

Fig. 5: leões sendo retirados (Correio da Manhã). Fig. 6: leões sendo transportados para a Fazenda São Geraldo (Luís Pinto/Acervo O Globo)

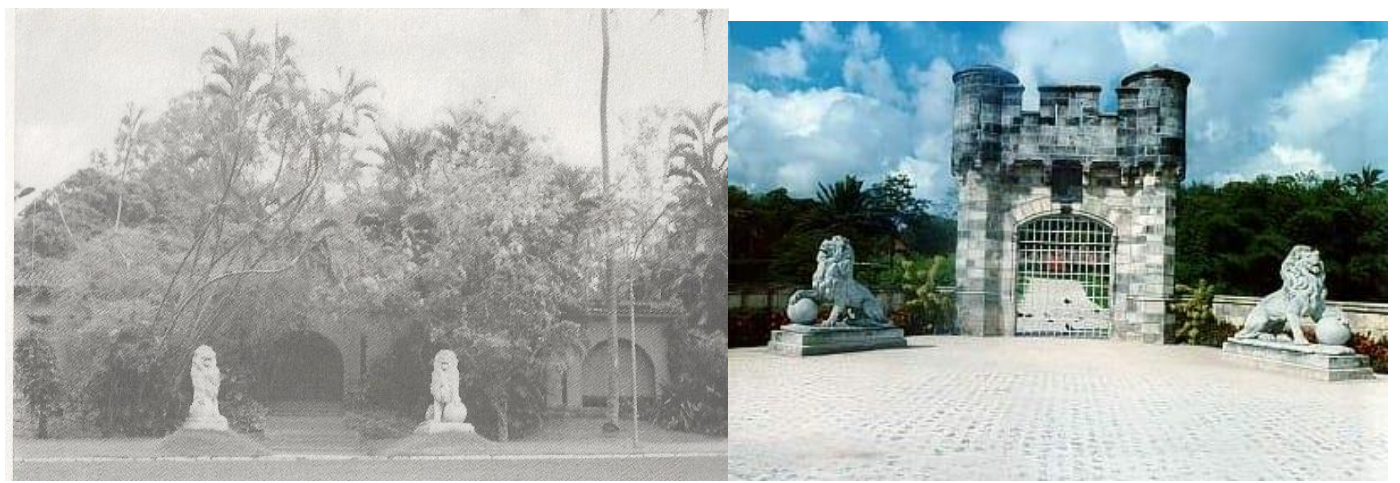

Fig. 7: leões na Fazenda São Geraldo (acervo Luís Carlos Franco). Fig. 8: leões no Instituto Ricardo Brennand (acervo IRB).

A intenção inicial da empresa Aghil para a grande cúpula de cobre era retirá-la intacta e vende-la por um preço alto. Porém, no decorrer da demolição perceberam que seriam necessários três guindastes com capacidade para levantar 100 toneladas cada, além de 20 dias de trabalho ininterrupto. Considerando o tempo necessário, os valores referentes aos alugueis das máquinas e o pagamento dos funcionários e técnicos que seriam envolvidos no desmonte, a empresa avaliou a empreitada em Cr\$1.000.000,00, o que seria 


\section{3}

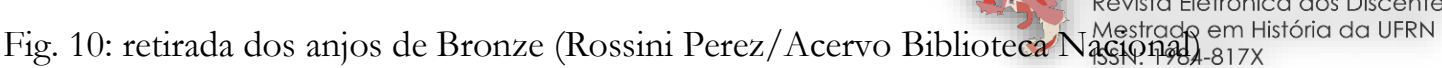

No dia 27/02/76 foi veiculada notícia no O Globo de que as últimas peças de valor ainda à venda na demolição do Palácio Monroe tinham sido reservadas por um grupo de seis arquitetos paulistas, interessados em objetos antigos para aproveitá-los em novas construções. O grupo, que não quis se identificar, se interessou pelo vitral octogonal com a inscrição “Ordem e Progresso", por outros vitrais de pequeno porte ainda disponíveis e oito brasões de cobre que enfeitavam a cúpula principal:

[...] além da cúpula menor que ficava na lateral do edifício. Antes de decidir por estas peças e realizar a proposta de Cr\$103.000,00 para a sua aquisição, os interessados circularam por muito templo pelo pátio do Monroe, onde está depositada a maioria dos objetos ainda à venda. Lá podem ser vistas grades trabalhadas, cerca de 22 brasões de cobre, umas 50 pequenas cabeças de leão em mármore, mais uma centena de balaústres também de mármore e mais umas 20 pequenas peças de adorno confeccionadas em cobre (O GLOBO, 27 fev. 1976, p. 7).

A venda deste material foi realizada de forma totalmente informal. Segundo entrevista concedida pelo fazendeiro mineiro que comprou as esculturas dos leões e os portões de ferro para decorar a sua propriedade em Uberaba, Luís Carlos de Adriano Franco, todas as tratativas eram feitas diretamente com o funcionário encarregado da demolição, "um português chamado seu Silva" que lhe foi apresentado no canteiro obras como sendo "O dono do Palácio" ${ }^{81}$. Foi o Sr. Silva que teria estipulado o preço de vários itens comprados pelo fazendeiro. Para a reportagem do Jornal O Globo, quando perguntado a respeito dos critérios para a fixação dos valores das peças, o Sr. Antônio Gonçalves da Silva teria afirmado que "não poderia falar muito. Os homens do Governo (fiscais do Ministério da Fazenda) pediram-me sigilo” (O GLOBO, 8 jan. 1976, p. 10). Para o Jornal Diário de Notícias, o Rio de Janeiro se desfalcava de seu acervo, mas, em compensação, "fazia a fortuna dos empresários da sucata e outros materiais do submundo dos negócios estranhos” (DIÁRIO DE NOTÍCIAS, 11 jan. 1976, p. 4).

Vale destacar que o contrato realizado com a empresa responsável por colocar o prédio abaixo não foi objeto de qualquer tipo de fiscalização pelo Poder Público, uma vez que as partes resultantes do desmonte do Palácio foram retiradas e vendidas sem qualquer avaliação anterior de sua relevância artística, estética ou histórica. A possibilidade da

81 Entrevista concedida para o documentário longa metragem CRÔNICA da demolição. Direção: Eduardo Ades. ImagemTempo. Rio de Janeiro - RJ, 2015. 90 min. 


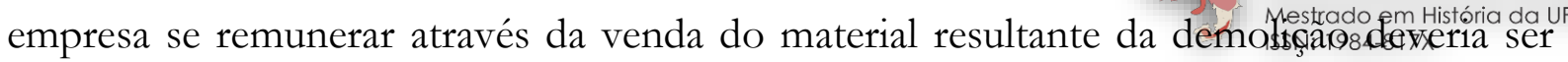
seguida dos critérios autorizadores deste descarte, sempre com a fiscalização dos órgãos responsáveis pela proteção do patrimônio cultural brasileiro, tais como o próprio IPHAN. Porém, pelo que afirmou o Sr. Silva "os homens do Governo" lhe pediram sigilo a respeito dos critérios para a fixação dos valores das peças e materiais do Palácio.

Ainda hoje, se quisermos comprar uma das peças que constituíam o acervo do Palácio basta oferecermos pela internet a quantia de R \$ 150.000,00 ao leiloeiro Horácio Ernani Rodrigues de Mello e teremos em casa a "fruteira do artista Sasportas, em bronze ormolú com 4 figuras de querubins, prato de cristal baccarat lapidado e lavrado com brasão da República"\$2 . O mesmo leiloeiro vendeu em 2013 oito balaustres de mármore carrara que eram do Palácio Monroe, por R \$ 8.000,00.

Algumas peças do Monroe conseguiram escapar deste desmonte ocorrido com a demolição. Em 08/01/76 foi noticiado que um funcionário do Itamarati tinha estado no Palácio para providenciar a retirada de duas placas de madeira que registravam o dia da instalação do Senado Federal com o objetivo de envia-las a capital (O GLOBO, 8 jan. 1976, p. 10). Já as mesas e cadeiras do antigo Senado também foram para Brasília, onde atualmente compõem o Museu da instituição.

Em 2015, o então coordenador do Museu do Senado, Alan Silva, mandou abrir diversas caixas de madeira que permaneceram lacradas durante quase 45 anos num depósito do próprio Senado, em Brasília. Para a surpresa de todos, dentro das caixas estavam 20 lustres de estilo rococó, repletos de ornamentos e detalhes feitos de ferro, latão e cristal que iluminavam os salões do Palácio Monroe. Todo este material descoberto foi restaurado para comporem o acervo do Museu. Alan Silva afirmou que quando chegaram a Brasília, as caixas que continham os lustres acabaram sendo desprezadas e esquecidas, pois "toda a atenção foi dada às que trouxeram escrivaninhas e cadeiras, que teriam utilidade para senadores e funcionários. Não era o caso dos lustres rococós" (WESTIN, 2015, online). A decisão de abrir as caixas somente em 2015 teve como motivação as comemorações dos 190 anos do Parlamento brasileiro, que ocorreram em 2016, quando o Museu do Senado organizou uma exposição com peças históricas de vários momentos da casa legislativa.

Realmente, o percurso do material oriundo das demolições é imprevisível,

82 Disponível em <https://www.ernanileiloeiro.com.br/peca.asp?ID=57226>. Acesso em: 24 out. 2017. 


\section{5}

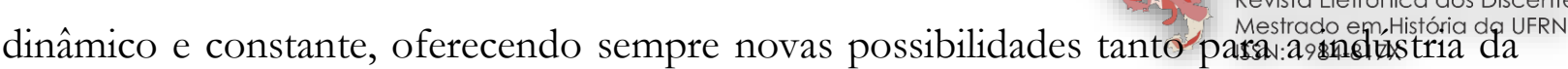
construção civil quanto para as feiras de antiguidades, leiloeiros, colecionadores e agências e institutos do patrimônio histórico e cultural. Como ensina Ulpiano Bezerra de Meneses, um objeto ou artefato possui somente propriedades de natureza físico-química, tais como forma, peso, textura, cor, etc. Nenhum atributo de sentido é inerente ao objeto. Estes atributos são "historicamente selecionados e mobilizados pelas sociedades e grupos nas operações de produção, circulação e consumo de sentido" (MENESES, 1998, p. 91).

\section{PALÁCIO MONROE: REFERÊNCIA CULTURAL E RESSONÂNCIA}

Segundo Maria Cecília Londres Fonseca (2001, p. 112) a expressão "referência cultural" é utilizada, majoritariamente, "em textos que têm como base uma concepção antropológica de cultura, e que enfatizam a diversidade não só da produção material, como também dos sentidos e valores atribuídos pelos diferentes sujeitos a bens e práticas sociais". Contudo, em que pese a noção de referencia cultural estar mais ligada aos aspectos da imaterialidade, esta categoria também pode ser relacionada com os bens materiais. Se olharmos para o Palácio Monroe sob a perspectiva de uma edificação elaborada num estilo arquitetônico eclético predominante e valorizado no Brasil nos primeiros anos da República, que tinha como pretensão simbolizar o alinhamento da nação com o mundo civilizado e que, além disso, ganhou o primeiro prêmio internacional da arquitetura brasileira, podemos considera-lo como um suporte material que se constituiu como uma referência cultural enquanto valorizado como uma marca distintiva por determinados grupos sociais. Ainda seguindo os caminhos indicados por Maria Cecília Londres Fonseca (2001, p. 113):

$\mathrm{O}$ ato de apreender referências culturais pressupõe não apenas a captação de determinadas representações simbólicas, como também a elaboração de relações entre elas e a construção de sistemas que falem daquele contexto cultural, no sentido de representá-lo. Nessa perspectiva, os sujeitos dos diferentes contextos culturais têm um papel não apenas de informantes como também de intérpretes de seu patrimônio cultural.

Percebe-se, portanto, que sob a perspectiva da noção de referência cultural, o peso material e simbólico daquilo que é considerado patrimônio pelos órgãos e institutos especializados possui uma dinâmica de atribuição de sentidos e valores ao longo do tempo. Ou seja, os bens culturais não valem por si mesmos, não têm um valor intrínseco: “o valor 


\section{6}

lhes é sempre atribuído por sujeitos particulares e em função de determi Mestrado em.História da URRN interesses historicamente condicionados". Continuando na esteira de Maria Cecília Londres Fonseca (2001, p. 112):

Levada às últimas consequências, essa perspectiva afirma a relatividade de qualquer processo de atribuição de valor - seja valor histórico, artístico, nacional etc. - a bens, e põe em questão os critérios até então adotados para a constituição de patrimônios culturais, legitimados por disciplinas como a história, a história da arte, a arqueologia, a etnografia, etc. Relativizando o critério do saber, chamava-se atenção para o papel do poder.

Marcia Chuva (2015), ao analisar como a noção de referência cultural foi introduzida nas práticas de preservação cultural brasileira nos anos 1970, ensina que:

Um bem cultural pode ser incluído na categoria de patrimônio quando são atribuídos a ele sentidos e significados que o torna referência para um grupo, que se identifica com aquele bem, sendo um elo entre todos aqueles que compõem esse grupo. Por isso, todo patrimônio se constitui a partir de uma forte carga simbólica, que é imaterial ou intangível (CHUVA, 2015, p. 25).

Contudo, não basta que um determinado círculo de intelectuais ou grupo de poder estabeleçam que um bem material seja considerado como uma referencia cultural. Neste ponto, entra em cena outra categoria importante quando se busca esmiuçar o conceito de patrimônio: a ressonância. A noção de referencia cultural, muito utilizada a partir da presidência de Aloísio Magalhães no IPHAN83, pressupõem sujeitos para os quais essas referências façam sentido. Trata-se, portanto, de uma subjetividade inerente a qualquer patrimônio cultural. Esta subjetividade ou imaterialidade do patrimônio se relaciona com a questão da ressonância, ou seja, com o grau de reconhecimento de um determinado patrimônio cultural junto aos diversos setores da população. Conforme os ensinamentos de José Reginaldo Gonçalves (2007, p. 19):

[...] um patrimônio não depende apenas da vontade e decisão políticas de uma agência de Estado. Nem depende exclusivamente de uma atividade consciente e deliberada de indivíduos ou grupos. Os objetos que compõem um patrimônio precisam encontrar 'ressonância' junto a seu público.

Para o historiador Stephen Greenblatt, citado por Gonçalves (2007), a ressonância está relacionada com a capacidade de um determinado objeto, prédio ou monumento

\footnotetext{
${ }^{83}$ Sob a presidência de Aloísio Magalhães, em 1975, foi fundado o Centro Nacional de Referência Cultural (CNRC). O objetivo era traçar um sistema referencial básico a ser empregado na descrição e análise da dinâmica cultural brasileira. Como resultado da fusão entre o Serviço do Patrimônio Histórico e Artístico Nacional (SPHAN) e o CNRC, em 1979, foi criado a Fundação Nacional Pró-Memória (FNPM).
} 
atingir um universo mais amplo, para além de suas fronteiras formais. Traestrado gm Hiśtória da UFRN de evocar no expectador as forças culturais complexas e dinâmicas das quais ele emergiu e das quais ele é, para o expectador, o representante" (GREENBLATT apud GONÇALVES, 2007, p. 19).

Os aspectos materiais, históricos e simbólicos do Palácio Monroe tiveram esta ressonância nos meios intelectuais, acadêmicos e profissionais, pois sua demolição reverberou nos corredores de diversas instituições e órgãos públicos, tais como o Instituto do Patrimônio Histórico e Artístico Nacional - IPHAN, o Instituto dos Arquitetos do Brasil - IAB, o Clube de Engenharia e o Instituto Histórico e Geográfico Brasileiro - IHGB. Porém, qual era o grau de ressonância do Monroe junto a população leiga? Ele era considerado pelos transeuntes apressados do centro da cidade do Rio de Janeiro como uma referência cultural?

O Jornal Ultima Hora veiculou interessante matéria a respeito do Monroe com o subtítulo "Povo é contra a demolição" (figura 11), afirmando que "embora não tenha argumentos técnicos, mas opinando livremente, o homem da rua é favorável à conservação do Palácio Monroe”. Para subsidiar esta afirmação, o periódico realizou uma enquete nas ruas do Passeio Público no Centro do Rio onde constatou que apenas "dez por cento dos entrevistados foram a favor da demolição do antigo prédio do Senado Federal". No entanto, segundo a matéria, mesmo aqueles que votaram a favor da derrubada frisaram que não gostariam de ver um espigão no lugar do Monroe. Apenas uma pessoa entrevistada pelo Jornal, “o Sr. Geraldo da Conceição, bombeiro, é de opinião que 'um edifício de 30 ou 40 andares ficaria melhor, mais de acordo com o Rio de hoje, cheio de progresso e de edifícios grandes". Para Paulo Ramos, então integrante do conjunto musical Arte e Samba, a demolição era um absurdo "porque devemos conservar os poucos monumentos que ainda temos e, apesar de o Palácio não ser tão velho assim, devemos defendê-lo, senão amanhã vão querer terminar com toda a nossa história só porque é velha". Já o bancário José Carlos pensava que os prédios antigos deveriam ser conservados não só por seu valor histórico como também por constituírem atração para o turista: "se Roma e Paris conseguiram conciliar a cidade velha com a moderna, por que iremos destruir o que ainda existe de arte e história entre nós?”, perguntou. A comerciária Márcia Cruz afirmou não gostar da aparência do Monroe, "muito sujo e quebrado, sem as escadarias que davam para a Avenida Rio Branco". Porém, opinou que o prédio deveria ficar de pé, pois não interferiu 


\section{8}

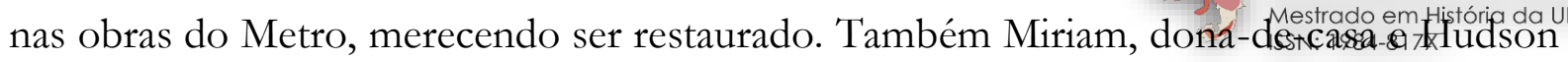
Antônio, cantor, eram favoráveis à permanência da antiga sede do Senado Federal, que segundo Hudson, "dá um toque de graça e beleza aqui na Cinelândia, já tão cheia de prédios altos e antiestéticos" (ULTIMA HORA, 11 jul. 1975, p. 8).

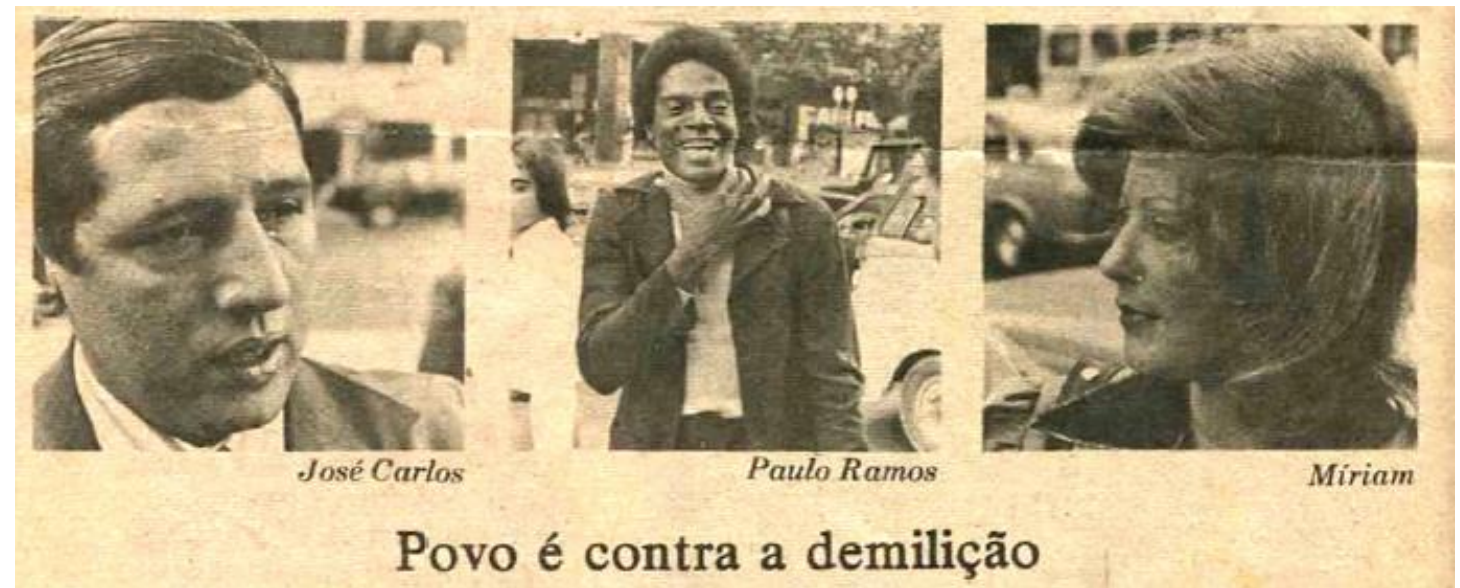

Fig. 11: recorte da matéria do Jornal Ultima Hora com as fotos de alguns entrevistados (Acervo Ultima Hora)

Esta singela e muito interessante reportagem mostra que a população estava bem atenda aos debates e argumentos que giravam em torno da preservação do patrimônio cultural da cidade e do Monroe, em especial. Fora dos salões das instituições representativas dos engenheiros e arquitetos e longe dos gabinetes do IPHAN, os entrevistados percebiam claramente o crescimento da cidade e sua falta de organização e de espaço, bem como a alteração da paisagem do centro comercial em decorrência da pressão imobiliária e das intervenções urbanísticas ocasionadas pelas obras de urbanização. Reconheciam, ainda, a importância histórica do Monroe e sabiam identificar as questões estéticas relacionadas à sua arquitetura.

\section{CONSIDERAÇÕES FINAIS}

A força da memória relacionada ao Palácio Monroe, ainda encontra alguma ressonância. No ano de 2017, o Instituto de Arquitetos do Brasil apresentou na página principal do seu sítio na internet uma enquete seguida de três opções de voto: "Qual ícone da arquitetura brasileira merecia ser reconstruído? 1- Palácio Monroe, no Rio de Janeiro destruído em 1976; 2- Pavilhões do Palácio do Anhangabaú, em São Paulo - destruídos entre 1950 e 1960; 3- Antiga Matriz de Boa Viagem do Arraial do Curral del Rey, em Belo 


\section{9}

rônica dos Discentes do

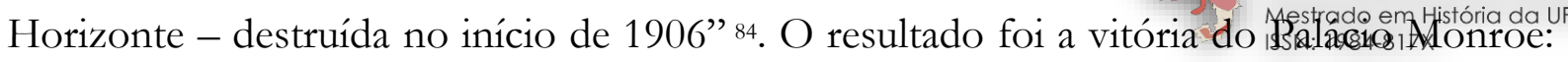

$50,7 \%$ contra $26,9 \%$ da segunda opção e $22,4 \%$ da terceira. É certo que os 3 prédios escolhidos para participarem da enquete possuem histórias e estilos totalmente diferentes. Porém, o resultado é um indicativo da forte ressonância ainda ocasionada pela demolição do Monroe.

Recentemente, no dia 11 de maio de 2017, o documentário longa-metragem a respeito o Palácio Monroe Crônica da Demolição, dirigido por Eduardo Ades, entrou no circuito comercial, apesar de já ter sido exibido no Festival do Rio em 2015. O filme foi escolhido pelo público como melhor documentário do $4^{\circ}$ Brasília International Film Festival - BIFF e realizou uma excelente pesquisa sobre o prédio, com raras imagens e diversas entrevistas com personalidades da arquitetura e da política, tais como Alexandre Nicolaeff, Cesar Maia, Humberto Barreto, Noel de Almeida, entre outros

Pelo que foi exposto neste artigo, a demolição do Palácio Monroe, realizada na década de 1970 de forma violenta e arbitrária, encontrou ressonância não somente perante os intelectuais e personalidades da engenharia e da arquitetura, como também na população da cidade. Porém, esta ressonância não teve força suficiente para enfrentar o então estado autoritário brasileiro e manter o prédio de pé. Apesar do Palácio não ter sido objeto de tombamento por parte do IPHAN quando apreciou a questão do conjunto arquitetônico remanescente da Avenida Central, podemos afirmar que o edifício possuía significação artística, estética, histórica e até mesmo turística, pois estava localizado na mesma área do Museu de Belas Artes, da Biblioteca Nacional e do Teatro Municipal. Ademais, é possível atribuir ao Monroe o valor de documento, pois representativo do estilo arquitetônico predominante ao longo implementação e consolidação da República em nosso país bem como de um período histórico possuindo, assim, um valor que refletia as escolhas e representações de uma determinada época.

O que chamou a atenção especificamente no caso do Palácio Monroe foi a violência simbólica que caracterizou a sua demolição. Afinal, tratava-se de um prédio público cuja arquitetura foi a primeira a receber uma premiação internacional e que abrigou o Senado federal por 35 anos. Infelizmente, estes e outros atributos não foram suficientes para a sua preservação diante do contexto político, econômico e urbano do país e da cidade

${ }^{84}$ Disponível em http://www.iab.org.br/. Acesso em 14 mai. 2017. 
do Rio de Janeiro na década de 1970. Porém, no campo da memória, o Palalastroado emp Histónia da duenN pois frequentemente é usado como um emblemático exemplo dos excessos praticados pelas autoridades em relação ao patrimônio público e cultural.

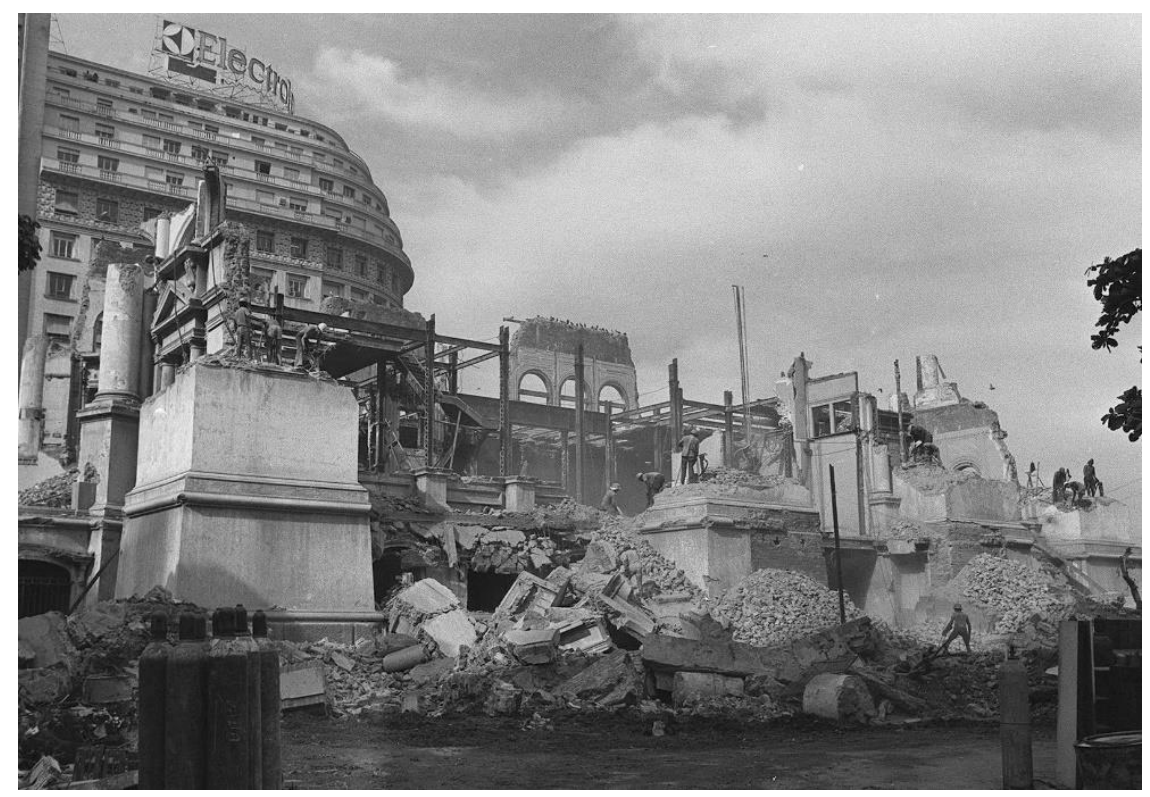

Fig.12: Palácio na fase final da demolição (Arquivo Público do Rio de Janeiro)

\section{REFERENCIAS BIBLIOGRÁFICAS}

AGUIAR, Louis de Souza. Palácio Monroe: da glória ao opróbrio. Rio de Janeiro: s.e., 1976.

ANDERSON, Benedict. Comunidades imaginadas: reflexões sobre a origem e a difusão do nacionalismo. São Paulo: Companhia das Letras, 2008.

ATIQUE, Fernando. O Patrimônio (Oficialmente) Rejeitado: A destruição do Palácio Monroe e suas repercussões no ambiente preservacionista carioca. In.: Simpósio Nacional da ANPUH - Associação Nacional de História, 2011, São Paulo. Anais eletrônicos... São Paulo: ANPUH Disponível em: <http://www.snh2011.anpuh.org/resources/anais/14/1308086788_ARQUIVO_ANPU H-versaofinal.pdf >. Acesso em: 11 fev. 2018.

CHUVA, Márcia. Da referência cultural ao patrimônio imaterial: introdução à história das políticas de patrimônio imaterial no Brasil. In: Reis, Alcenir e Figueiredo, Betânia. Patrimônio Imaterial em Perspectiva. Belo Horizonte: Fino Traço, 2015.

FONSECA, Maria Cecília Londres. Referências culturais: bases para novas políticas de patrimônio. Boletim de Políticas Setoriais. Brasília: IPEA, n. 02, 2001, p. 111-120. Disponível

em: http://www.ipea.gov.br/agencia/images/stories/PDFs/politicas_sociais/referencia_2.p df. Acesso em: 29 mar. 2018.

FRIDMAN, Sergio A. Palácio Monroe: da construção a demolição. Rio de Janeiro: S.A. Fridman, 2011. 


\section{1}

GONÇALVES, José Reginaldo S. "Ressonância, Materialidade e Subjetiviedstrdodo em Histéria da UFRN como patrimônios". In: Antropologia dos objetos: coleções, museus e patrimônio. Rio de Janeiro, 2007.

GOYENA, Alberto. A demolição em sete obras: patrimônio, arquitetura e esquecimento. 2015. 228 f. Tese (Doutorado em Antropologia) - UFRJ/IFCS/Programa de Pós-Graduação em Sociologia e Antropologia, Rio de Janeiro, 2015.

Rituais urbanos de despedida: reflexões sobre procedimentos de demolição e práticas de colecionamento. p. 3. In: Seminário Internacional, Museografia e Arquitetura de Museus: Identidades e Comunicação, 2., 2010, Rio de Janeiro. Anais eletrônicos... Rio de Janeiro: UFRJ. Disponível em: $<$ http://www.arquimuseus.arq.br/anaisseminario_2010/eixo_i/p1-artigo-alberto-goyena-26-10.pdf>. Acesso em: 29 mar. 2018. HOBSBAWM, Eric. Nações e Nacionalismos desde 1780. 4a. ed. Rio de Janeiro: Paz e Terra, 2004.

JANCSÓ, István. Brasil: formação do Estado e da Nação. Apresentação. São Paulo: Hucitec-Fapesp, 2003.

MENESES, Ulpiano T. Bezerra de. Memória e Cultura Material: documentos pessoais no espaço público. Estudos Históricos. Rio de Janeiro, v. 11, n. 21, p. 89-104, 1998, p. 91. WESTIN, Ricardo. Senado resgata lustres que iluminavam Palácio Monroe. Senado Noticias. Brasília, 29 set. 2015. Disponível em <https://www12.senado.leg.br/noticias/materias/2015/09/25/senado-resgata-lustresque-iluminavam-palacio-monroe $>$. Acesso em: 30 out. 2017. 